Supporting Information

\title{
Co-production of Value-Added Lube Base Oil and Green Diesel from Natural Triglycerides via a Simple Two-Step Process
}

Mingyu Jin,${ }^{\dagger}$ Mi-Eun Lee, ${ }^{\ddagger}$ Minji Seo, ${ }^{\dagger}$ Jae-Kon Kim, ${ }^{\ddagger}$ Sheng Li, ${ }^{\dagger}$ and Minkee Choi ${ }^{*}, \dagger$

'Department of Chemical \& Biomolecular Engineering, Korea Advanced Institute of Science and Technology (KAIST), 291 Daehak-ro, Yuseong-gu, Daejeon, 34141, Republic of Korea

FAlternative Fuel R\&D Team, Korea Petroleum Quality \& Distribution Authority, 33 Yangcheong 3-gil, Ochang-eup, Cheongju-si, Chungcheongbuk-do, 28115, Republic of Korea
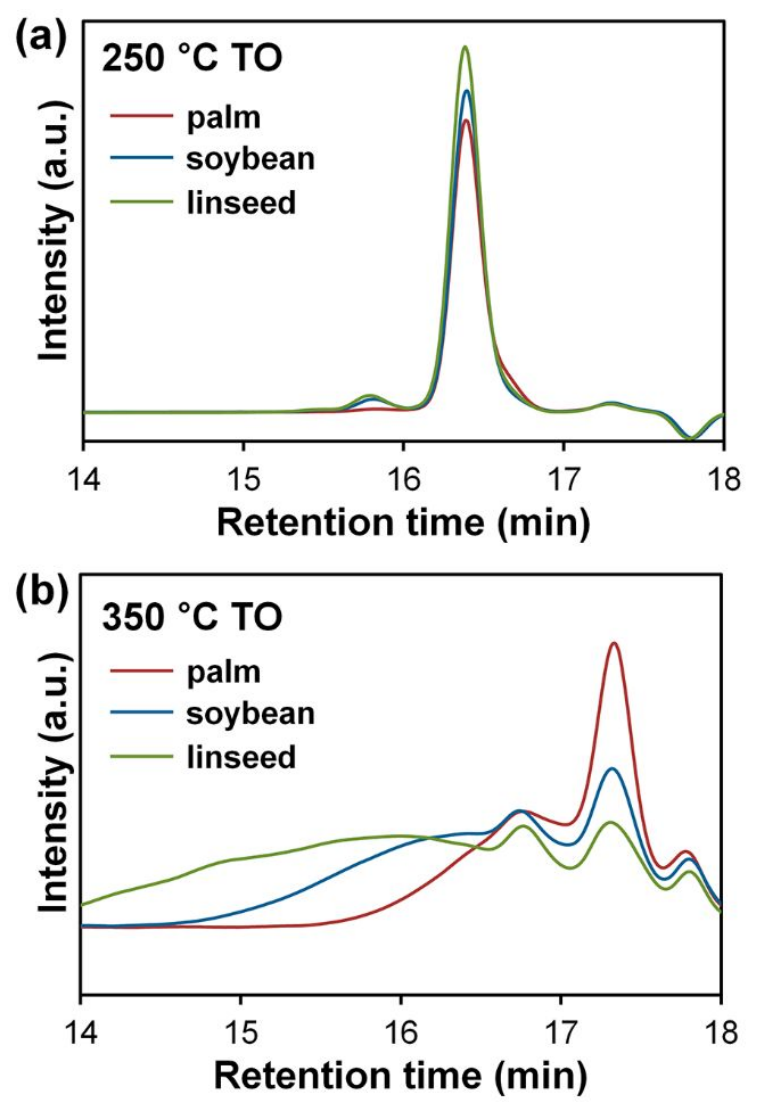

Figure S1. GPC profiles of thermally oligomerized triglycerides at (a) $250{ }^{\circ} \mathrm{C}$ and (b) $350{ }^{\circ} \mathrm{C}$. 


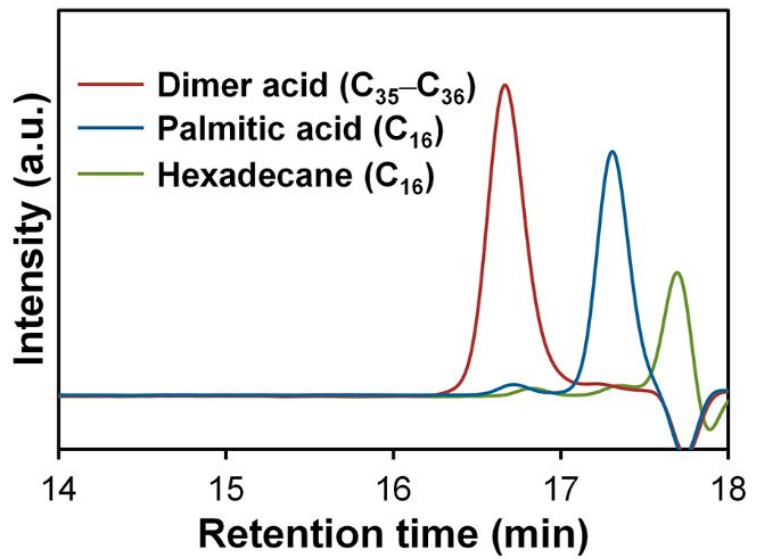

Figure S2. GPC profiles of dimer acid $\left(\mathrm{C}_{35}-\mathrm{C}_{36}\right)$, palmitic acid $\left(\mathrm{C}_{16}\right)$, and hexadecane $\left(\mathrm{C}_{16}\right)$.

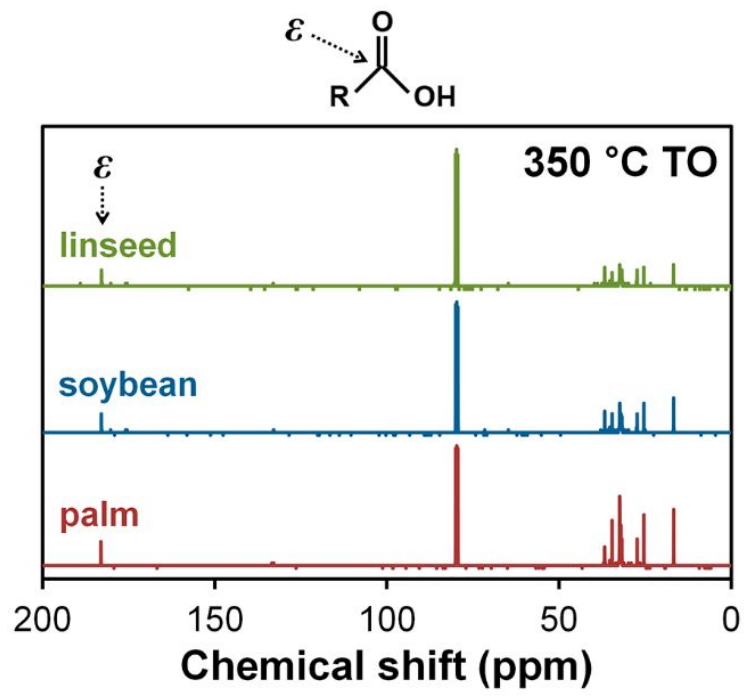

Figure S3. ${ }^{13} \mathrm{C}$ NMR spectra of the thermally oligomerized triglycerides at $350{ }^{\circ} \mathrm{C}$. 


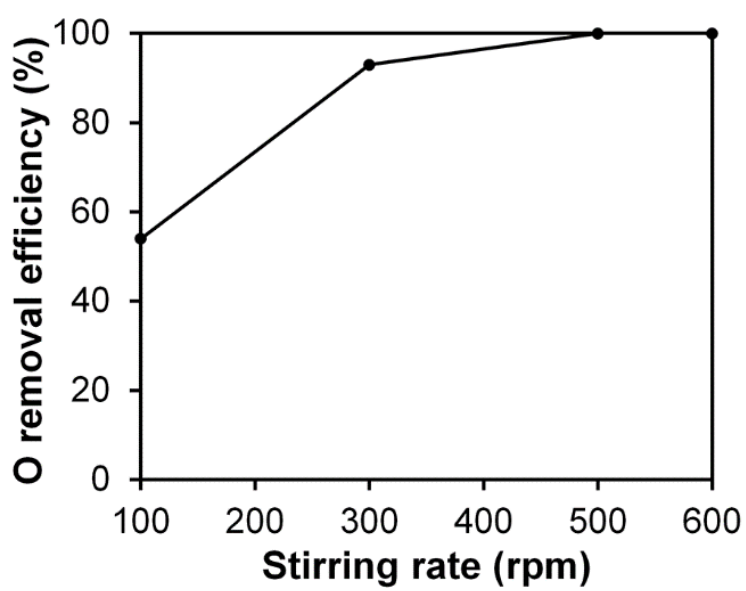

Figure S4. Deoxygenation efficiency as a function of the stirring rate (reactant: linseed-TO, catalyst: $\mathrm{Pt}-\mathrm{MoO}_{\mathrm{x}} / \mathrm{TiO}_{2}$, reaction conditions: $320^{\circ} \mathrm{C}, 50$ bar $\mathrm{H}_{2}, 4 \mathrm{~h}$ ).

(a)

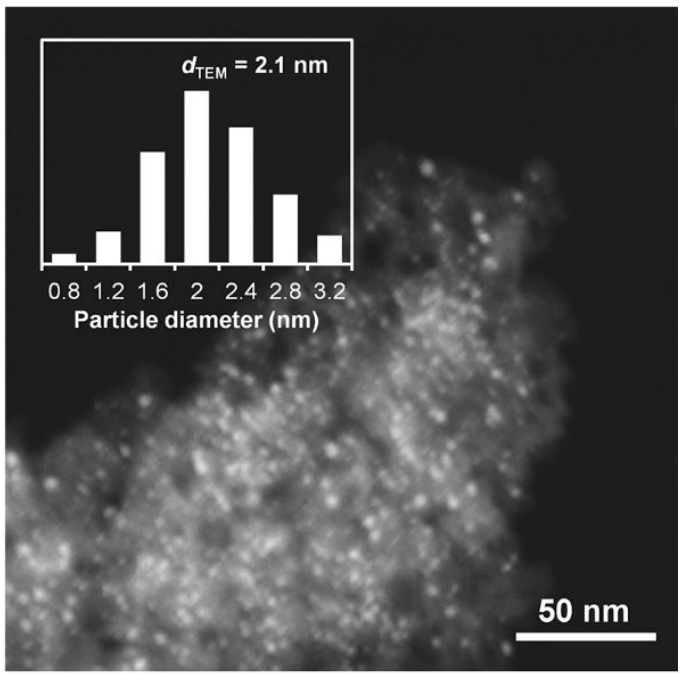

(b)

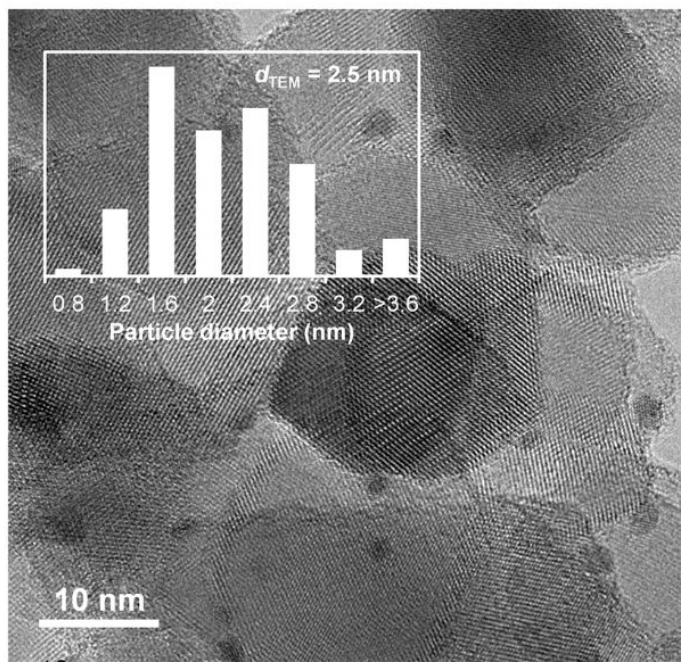

Figure S5. (a) HAADF-STEM image and particle size distribution of $\mathrm{Pt} / \gamma-\mathrm{Al}_{2} \mathrm{O}_{3}$ and (b) TEM image and particle size distribution of $\mathrm{Pt} / \mathrm{TiO}_{2}$. 


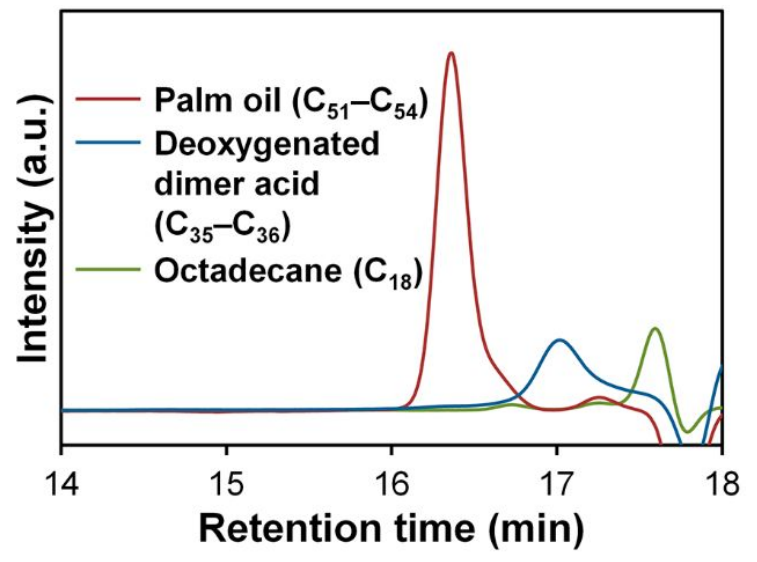

Figure S6. GPC profiles of octadecane $\left(\mathrm{C}_{18}\right)$, deoxygenated dimer acid $\left(\mathrm{C}_{35}-\mathrm{C}_{36}\right)$, and palm oil $\left(\mathrm{C}_{51}-\mathrm{C}_{54}\right)$.

Table S1. Elemental Compositions of the Deoxygenated Products of Thermally Oligomerized Triglycerides

\begin{tabular}{lcccc}
\hline \multirow{2}{*}{ Sample } & \multicolumn{4}{c}{ Elemental Composition (wt\%) } \\
\cline { 2 - 4 } & $\mathrm{C}$ & $\mathrm{H}$ & $\mathrm{O}$ & \\
\hline palm-DO & 85.1 & 14.9 & n.d. & 2.10 \\
soybean-DO & 85.1 & 14.9 & n.d. & 2.10 \\
soy + lin-DO & 85.2 & 14.8 & n.d. & 2.08 \\
linseed-DO & 85.3 & 14.7 & n.d. & 2.06 \\
\hline palm-TO-DO & 85.1 & 14.9 & n.d. & 2.10 \\
soybean-TO-DO & 85.3 & 14.7 & n.d. & 2.06 \\
soy + lin-TO-DO & 85.3 & 14.7 & n.d. & 2.06 \\
linseed TO-DO & 85.6 & 14.4 & n.d. & 2.01 \\
\hline${ }^{\text {a Molar ratio }}$ & & & &
\end{tabular}

